Schweizerische Gesellschaft für Ultraschall in der Medizin Società Svizzera di Ultrasonologia in Medicina Société Suisse d'Ultrason en Médecine

\title{
Taskforce Tarmed SGUM
}

Der TARDOC-Entwurf liegt immer noch beim Bundesrat. Dieser hat wohl wegen der aktuellen Situation andere Prioritäten.

Beat Dubs

Leiter Taskforce Tarmed 